\title{
Southern Hemisphere Climate Modes: ENSO and Indian Ocean Dipole
}

8th ICP Conference, Biarritz, France, 6-10 September 2004

During the 8th International Conference for Paleoceanography, a special workshop (Conveyor: Anne Müller, University of Queensland, Australia) was held over two afternoons on Southern Hemisphere Climate Modes. The workshop, with approximately 50 participants over two days, had a strong focus on the ENSO and Indian Ocean Dipole modes. Speakers included Luc Beaufort (Cerege Marseille, France), Tom Koutavas (MIT, USA), Rosalind Rickaby (University of Oxford, UK), Anne Müller (University of Queensland, Australia), Masanobu Yamamotu (Hokaido, Japan), Helen McGregor (Bremen University, Germany), Timothee Ourbak (Bordeaux University, France), and Miriam Pfeiffer (GEOMAR Kiel, Germany). The outcome of this workshop was a summary of current knowledge and gaps in the understanding of Southern Hemisphere climate modes. As an example figure 1 provides an overview of Holocene records of climate change. It was agreed that a focus of future research should be frequencies of ENSOlike climate mean states over glacial cycles, the occurrence of the Younger Dryas in the Southern Hemisphere, the possibility of La Niña-like sea surface patterns, for example, during the Early Holocene, the theory of a suppressed ENSO system during the mid-Holocene, the timing of the onset of the modern ENSO, and the interaction and teleconnection of ENSO and

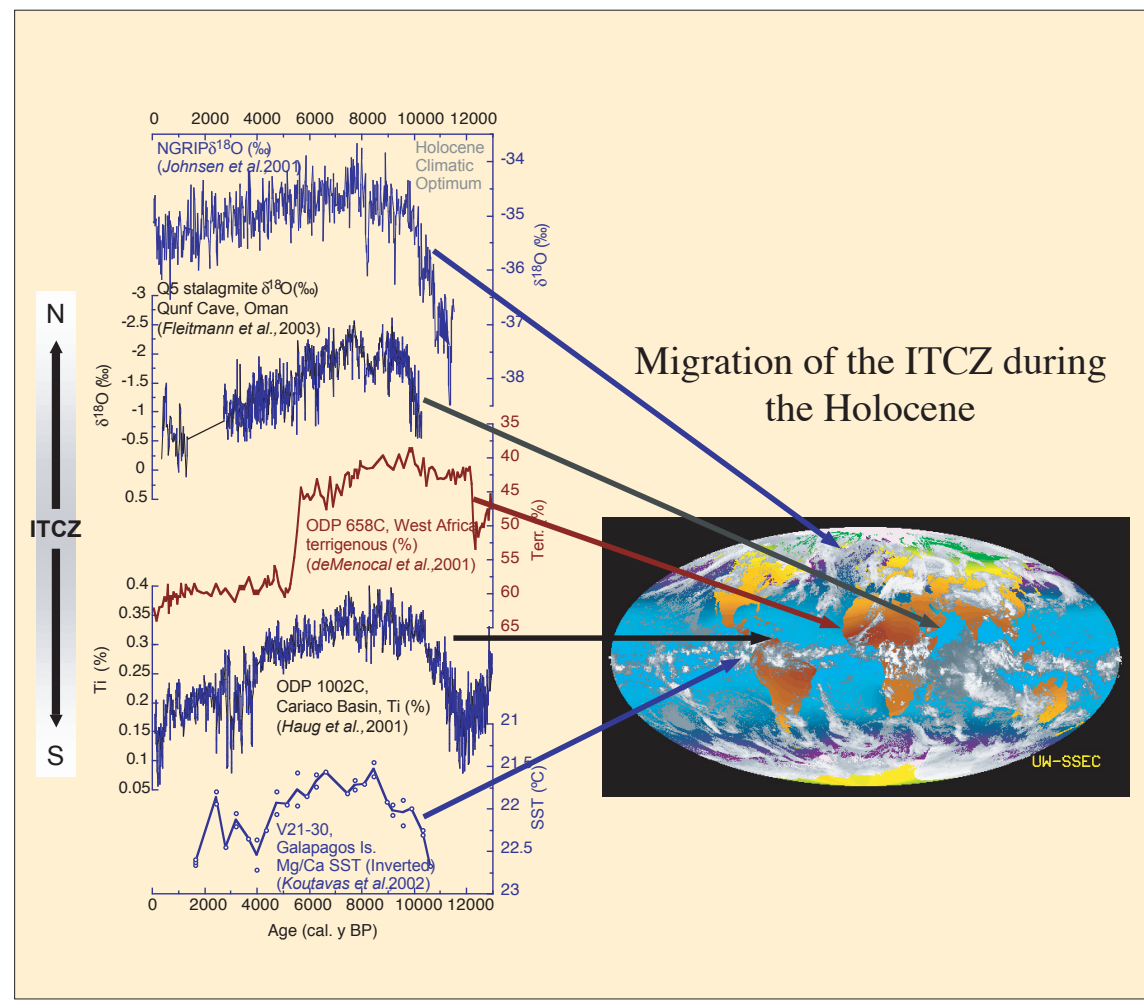

Fig. 1: Holocene records of climate change from (top to bottom) Greenland (Johnsen et al., 2001), the Arabian Peninsula (Fleitmann et al., 2003), West Africa (deMenocal et al. 2000), the Cariaco Basin (Haug et al., 2001) and the Galapagos Islands (Koutavas et al., 2002). The cooling trend over Greenland is accompanied by trends to more arid conditions in the northern tropics since the early-middle Holocene. Specifically, oxygen isotopic enrichment of stalagmites from Oman, rising aeolian inputs in marine sediments off West Africa, and decreasing titanium in Cariaco basin sediments, all indicate an effective decrease in rainfall over the course of the Holocene. These trends are consistent with a progressive southward migration of the Intertropical Convergence Zone (ITCZ) over the Atlantic and Indian Oceans. Cooler sea surface temperatures near the Galapagos Islands between 4,000 and 9,000 years ago indicate increased upwelling and support a more northerly ITCZ in the Pacific as well. The base map shows cloud observations during April 1998, with a prominent circum-global ITCZ near the equator.

Indian Ocean Dipole modes over geological time, and in particular recent time periods covered by paleoproxies such as corals. The participants also agreed that special attention should be given in the future to the use of, and differentiation between, terminology such as ENSO-like mean states and ENSO-variability

\section{AnNe Müller}

University of Queensland, Australia uqamuell@mailbox.uq.edu.au

\section{Holocene Climate Variability and Climate Forcing}

HOLIVAR WoRKSHop, Kastanienbaum, SWITZERLANd, 23-25 SEPTEMber 2004

On 23 September 2004, some 40 scientists met for 2.5 days in Kastanienbaum, Switzerland, to discuss Holocene climate variability and climate forcing within the framework of the HOLIVAR (Holocene Climate Variability) project.

The main objectives of this workshop were to identify and quantify the major forcing factors during the Holocene, to collect evidence for forcing from paleoclimate data, to discuss the role of models in linking climate forcing with climate response, and to develop strategies on how to improve our knowledge of past forcing. The climate system is driven by solar radiation. At the top of the atmosphere, about $30 \%$ of the total incoming solar power is reflected back into space, the rest is dissipated within the Earth system and eventually reemitted as infrared radiation. Since the largest input of solar radiation occurs in the equatorial region, the climate system continuously transports 


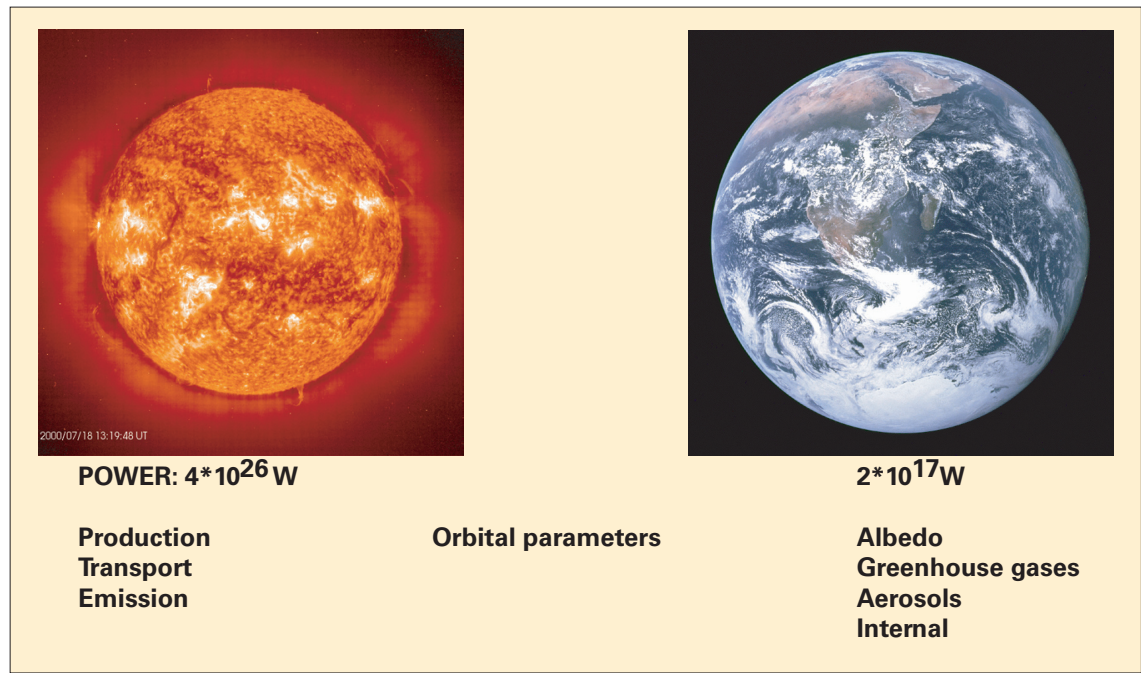

Fig. 1: The Sytem Sun-Earth and related main potential causes for climate changes..

energy through the atmosphere and the oceans towards the poles trying to reach a thermodynamic equilibrium. Any change within this complex system of processes causes either a change in the total power reaching the Earth or in its relative distribution within the Earth system, and therefore leads to climate changes. The main potential causes are listed in figure 1 .

All causes of climate change are characterized by relatively large uncertainties, except for two. According to the very robust standard solar model, the energy production in the core of the Sun increases extremely slowly and can therefore be considered as stable for the Holocene period. The distance Sun-Earth, the tilt of the Earth's axis and its precession are affected by the gravitational forces of the other planets and can be calculated with high precision for the past and the future. The variability of all the other potential forcing factors is not yet well understood.

Direct measurements of solar irradiance carried out by satellitebased radiation monitors show that solar irradiance changes in phase with the 11-year Schwabe sunspot cycle. However, the effect is small. During a Schwabe cycle, the average total annual irradiance varies by about $1.5 \%$ o. On the other hand, the UV part of the spectrum exhibits much larger changes, which affect the ozone layer and stratospheric chemistry. An important question is whether larger changes occurred at times when the average solar activity was considerably different, as for example during the Maunder Minimum (1645-1715), when sunspots were almost completely absent. In fact, there is growing evidence that on longer time scales, the variability in solar irradiance is larger than during the short instrumental period. The strongest evidence comes from the cosmogenic radionuclides $\left({ }^{10} \mathrm{Be},{ }^{14} \mathrm{C}\right)$. Their production rate in the atmosphere is modulated by solar activity. Records from ice cores $\left({ }^{10} \mathrm{Be}\right)$ and tree rings $\left({ }^{14} \mathrm{C}\right)$ offer the unique possibility of tracing changes in solar activity all the way back through the Holocene. However, there is no physical model available yet to quantitatively link solar activity with solar irradiance.

Forcing by greenhouse gases became an important issue with the burning of large amounts of fossil fuel. Presently, the main open question is how the various sources and sinks will affect the atmospheric concentration during the next few decades. But also the ice-core derived history of greenhouse gas variations during the last 10,000 years still gives rise to some puzzling data. On the one hand, reconstructions of $\mathrm{CO}_{2}$ concentrations derived from paleo stomata frequency records show unexpectedly large amplitudes on comparably short time scales. On the other hand, even the standard model of $\mathrm{CO}_{2}$ during the Holocene is not really understood yet. The $20 \mathrm{ppm}$ drop down to 260 ppm between 10 and 8 kyr was followed by a slow rise to modern pre-industrial levels. Several hypotheses have been formulated to explain this evolution of the most important greenhouse gas. The hope to constrain the role of these different processes by additional $\delta^{13} \mathrm{C}$ measurements made on the $\mathrm{CO}_{2}$ from ice turns out to be extremely difficult. The possibility of an early influence of man on $\mathrm{CH}_{4}$ and $\mathrm{CO}_{2}$ by agriculture and deforestation as suggested by Ruddiman (PAGES News 2004/1) is interesting, however the majority of evidence seems to argue against such a possibility, in particular for $\mathrm{CO}_{2}$.

The effects of aerosols, which are also strongly related to anthropogenic activities during the past century, are difficult to quantify for two main reasons. Firstly, their radiative properties depend on many different parameters and vary with time. Secondly, by analyzing ice cores, it is extremely difficult to estimate the relevant aerosol properties of past volcanic eruptions and dust picked up by wind in arid areas.

Climate models play a crucial role in estimating the amplitude of the response of the different forcings and their spatial patterns. However, models are far from perfect and may lack important mechanisms. Since 10,000 years is too long for complex model runs, a promising strategy could be to study in detail time slices that are relatively well documented regarding one single forcing factor and spatial climate response.

\section{GeoRg HofrmanN}

LSCE, Paris, France

georg.hoffmann@cea.fr

\section{JÜRG BEER}

EAWAG, Dübendorf, Switzerland beer@eawag.ch 